\title{
A Zeroth-Order Resonance Patch Antenna for Dual Band Operations with Broad E-plane Beam Widths
}

\author{
Krushna A. Munde \\ P. G. Dept., MBES College of Engineering, \\ Ambajogai, India, 431517.
}

\begin{abstract}
In this paper, design of probe fed zeroth order resonance (ZOR) antenna with dual frequency operation is presented. The mushroom structure is placed at the center of the geometry and the grounded via to have the desired ZOR response. The feed is connected between the inner ring and the mushroom structure. There are several ZOR antennas are available in literature with only one resonant frequency. However, in this work we presented ZOR antenna which excites dual resonances. The second resonance is obtained by placing two stubs and an outer ring. Also, it may be noted that we get nearly broader E-plane beamwidths (112 and 90 degrees) at both the resonance frequencies. The bandwidth of $7.8 \%$ at second resonant frequency was obtained as compared to the conventional patch antennas $(2 \sim 3 \%)$. At first resonance only narrow band performance was observed. Measured results fairly agree with the simulated data.
\end{abstract}

Keywords - Half power beam width (HPBW), Hybrid, Zeroth-order resonance (ZOR) mode, Metamaterials.

\section{INTRODUCTION}

In trans-receivers, planar antennas play a very important role in the field of wireless communications. Some of them are microstrip patch antennas, slot antennas, and folded dipole antennas with each type having their own properties and usage. But, the microstrip patch antennas have been the most popular antennas in modern wireless communication systems as they have several desirable attributes, such as a low-profile planar configuration, a light weight, a simple design principle, and a low fabrication cost [1-2]. However, the serious problem of patch antennas is their narrow bandwidth due to surface wave losses and large size of patch for better performance and also narrow scanning range. This weakness has created a need for an antenna with an enhanced beamwidth and small in size. To realize a broad beamwidth, many antennas using the various techniques have been reported. For example, by using the phase array patch structures [3], the multilayered structures [4-6] or the parasitic radiators [7-8], it is possible to design the patch antennas with a broad beamwidth. However, they have several limitations such as a larger size, a difficult design, and a multi-layered structure. These characteristics can be achieved using ZOR antennas. For example, the antennas utilize the zeroth-order resonance (ZOR) mode of the mushroom structure and the $\mathrm{TM}_{010}$ modes of the conventional rectangular patch are presented in [9-10]. The detailed theory on ZOR can be found in [11-17].

\author{
Veeresh G. Kasabegoudar \\ P. G. Dept., MBES College of Engineering, \\ Ambajogai, India, 431517.
}

In this work, dual frequency ZOR antenna is presented. The antenna presented in this work is taken from [12]. However, the antenna presented in [12] offers resonance only at one frequency. The antenna presented here is similar to [12] with an additional ring and two stubs to have second resonance. Also, by modifying the stub positions dual band characteristics can be obtained. The antenna is simulated using Ansoft's High Frequency Structure Simulator (HFSS) v.13 [18]. More details on this geometry are discussed in subsequent sections. Section 2 presents the geometry structure of the proposed antenna. Design and optimization procedure of the proposed antenna is presented in Section 3. Section 4 presents the validation of the fabricated prototype and discussions on the measured results are also presented there. Finally, conclusions of this study are presented in Section 5.

\section{ANTENNA GEOMETRY}

Figure 1(a) shows the basic geometry of proposed dual frequency ZOR patch antenna. Substrate used for the design is a glass epoxy (FR 4) with thickness of $3.175 \mathrm{~mm}$, dielectric constant of 4.4, and a loss tangent equal to 0.01 . The detailed optimization procedure of the proposed antenna and its optimum dimensions, and characteristics are presented in Section 3. All parameters of the geometry are indicated in Figure 1(a).

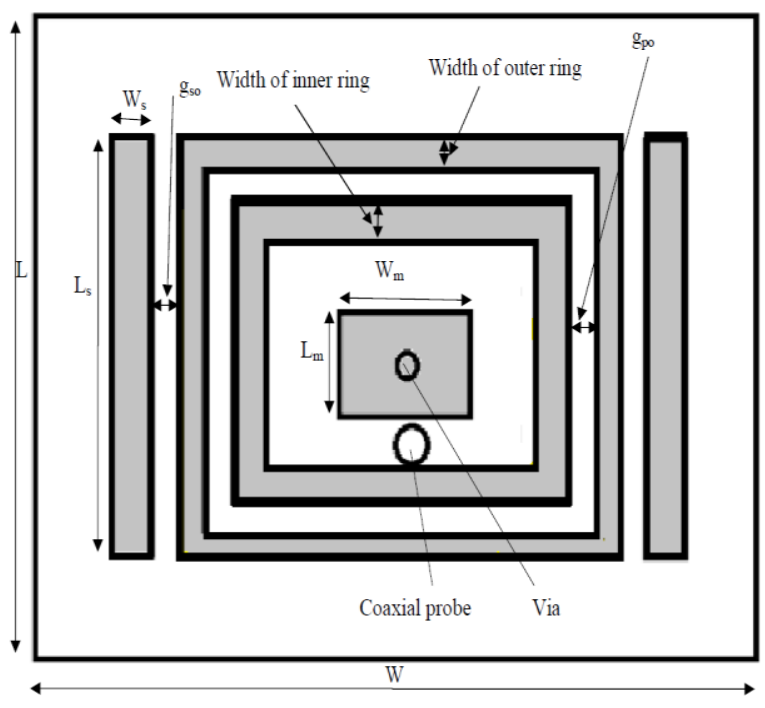

(a) Geometry 


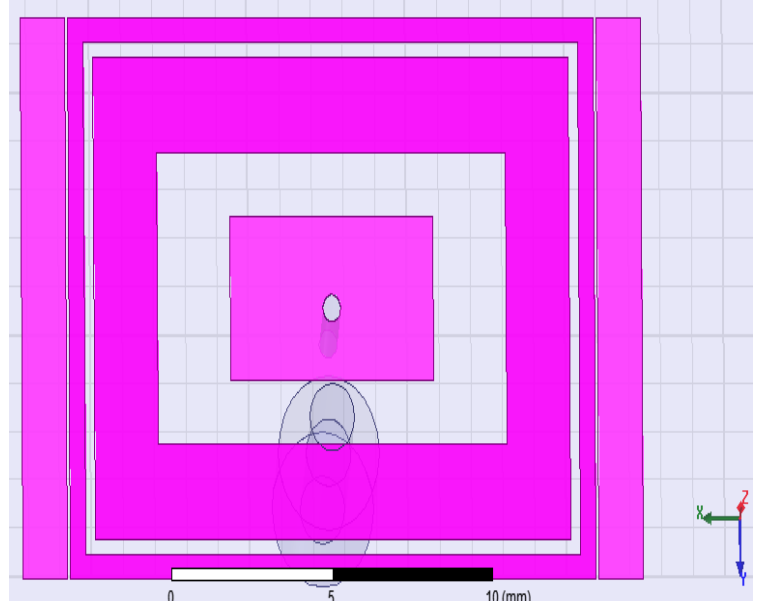

(b) Simulation setup

Figure 1: Geometry of proposed dual frequency ZOR patch antenna.

\section{GEOMETRY OPTIMIZATION AND DISCUSSIONS}

In this section parametric study is conducted to optimize the proposed antenna. The key design parameters used for the optimization are length of the stub, width of the stub, gap between stub and outer ring, and inner ring size. The detailed analysis of these parameters is investigated in the following subsections. All simulations were carried out with HFSS software (pl. ref. its setup in Figure 1(b)) which is a Finite Difference Time Domain (FDTD) based electromagnetic (EM) software.

\subsection{Effect of Stub}

\subsubsection{Effect of Length}

Two stubs are showed in Figure 1(a). The lengths of these two stubs are changed from $11 \mathrm{~mm}$ to $12.2 \mathrm{~mm}$ in steps of $0.3 \mathrm{~mm}$ keeping all the parameters constant. Return loss characteristics of these changes are given in Figure 6 and its effects are presented in Table 1. From this study it can be noted that the second resonance is shifted towards right as the value of length changes with first resonance unchanged.

Table 1: Resonant frequency deviation due to variation in the length of stub (Slot hole kept constant)

\begin{tabular}{|l|l|l|l|l|l|}
\hline $\begin{array}{l}\text { Length of stub } \\
(\mathbf{m m})\end{array}$ & 11 & 11.3 & 11.6 & 11.9 & 12.2 \\
\hline $\begin{array}{l}\text { First Resonant } \\
\text { Frequency }\left(\boldsymbol{f}_{\mathbf{r} 1}\right) \\
(\mathbf{G H z})\end{array}$ & 4.42 & 4.42 & 4.42 & 4.42 & 4.42 \\
\hline $\begin{array}{l}\text { Second Resonant } \\
\text { Frequency }\left(\boldsymbol{f}_{\mathbf{r} 2}\right) \\
(\mathbf{G H z})\end{array}$ & 7.28 & 7 & 6.92 & 6.88 & 6.7 \\
\hline
\end{tabular}
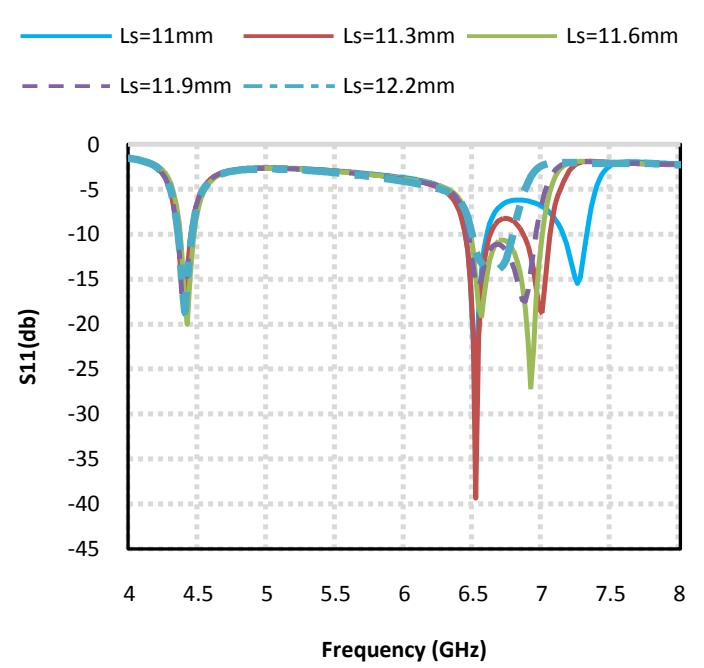

Figure 2: Return loss vs. frequency plot for variation in length of stub.

\subsubsection{Effect of Width}

In this the width of stubs changes from $1 \mathrm{~mm}$ to $1.8 \mathrm{~mm}$ in steps of $0.2 \mathrm{~mm}$ keeping all other parameters constant. Return loss characteristics of these changes given in Figure 3 and its data values are presented in Table 2. From this study it is observed that the second resonance is shifted towards left as the value of width changes with keeping first resonance unaltered.

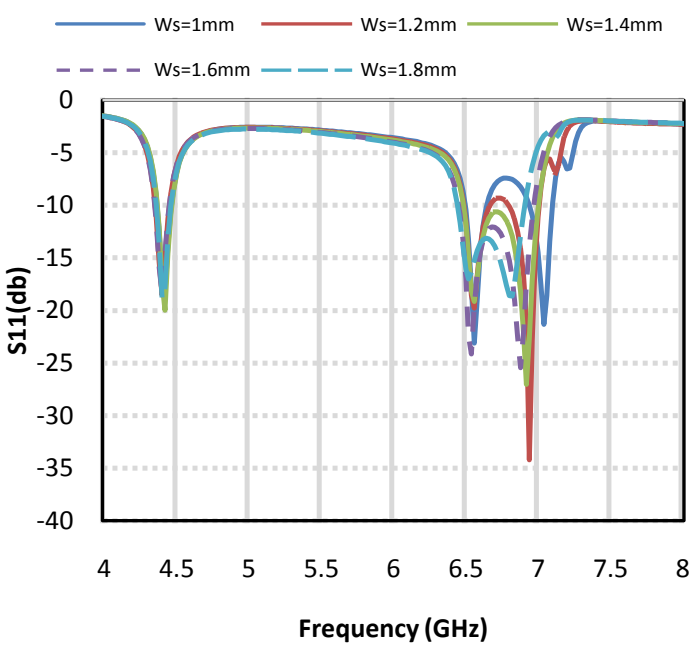

Figure 3: Return loss vs. frequency plot for variation in width of stub.

Table 2: Resonant frequency deviation due to variation in the width of stubs (Inner ring kept constant)

\begin{tabular}{|l|l|l|l|l|l|}
\hline Width of stub $(\mathbf{m m})$ & 1 & 1.2 & 1.4 & 1.6 & 1.8 \\
\hline $\begin{array}{l}\text { First Resonant } \\
\text { Frequency }\left(\boldsymbol{f}_{\mathbf{r} 1}\right)(\mathbf{G H z})\end{array}$ & 4.42 & 4.42 & 4.42 & 4.42 & 4.42 \\
\hline $\begin{array}{l}\text { Second Resonant } \\
\text { Frequency }\left(\boldsymbol{f}_{\mathbf{r} 2}\right)(\mathbf{G H z})\end{array}$ & 7.04 & 6.94 & 6.92 & 6.88 & 6.78 \\
\hline
\end{tabular}




\subsubsection{Effect of Gap}

In another effort gap between the stubs and an outer ring changed from $0.1 \mathrm{~mm}$ to $0.5 \mathrm{~mm}$ in steps of $0.1 \mathrm{~mm}$ with other parameters are kept constant. Return loss characteristics of these changes given in Figure 8. From Table 3 it can be noticed that the second resonance is shifted towards left as the value of gap between stubs and outer ring changes. As explained in earlier paragraphs, here also the first resonant frequency remains constant.

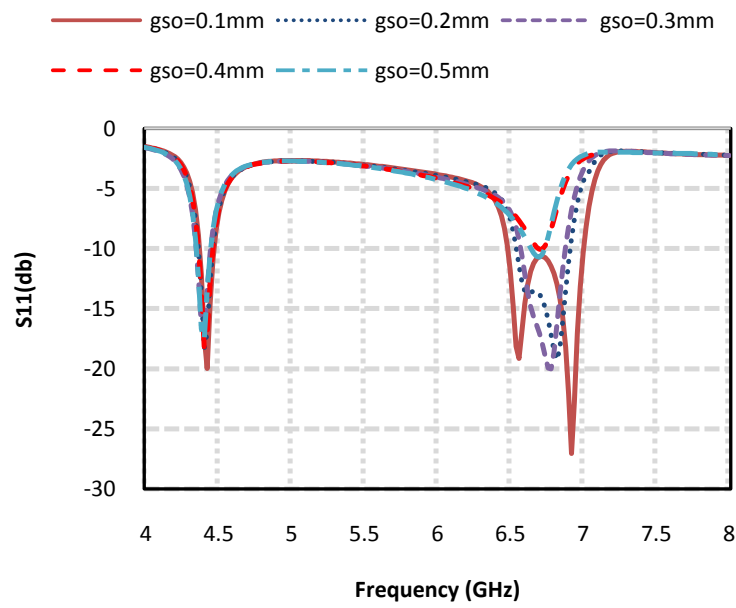

Figure 4: Return loss vs. frequency plot for variation in gap between outer ring and stub.

Table 3: Resonant frequency deviation due to variation in the gap of stubs (Inner ring kept constant)

\begin{tabular}{|l|l|l|l|l|l|}
\hline $\begin{array}{l}\text { Gap between } \\
\text { stubs and outer } \\
\text { ring (mm) }\end{array}$ & 0.1 & 0.2 & 0.3 & 0.4 & 0.5 \\
\hline $\begin{array}{l}\text { First Resonant } \\
\text { Frequency }\left(f_{\text {r1 }}\right) \\
(\mathbf{G H z})\end{array}$ & 4.42 & 4.42 & 4.42 & 4.42 & 4.42 \\
\hline $\begin{array}{l}\text { Second Resonant } \\
\text { Frequency }\left(\boldsymbol{f}_{\mathbf{r} 2}\right) \\
(\mathbf{G H z})\end{array}$ & 6.92 & 6.8 & 6.76 & 6.7 & 6.68 \\
\hline
\end{tabular}

\subsection{Effect of Inner Ring}

The width of inner ring is changed from $2 \mathrm{~mm}$ to $3 \mathrm{~mm}$ in steps of $0.2 \mathrm{~mm}$ with all other parameters kept constant. Return loss characteristics of this study are presented in Figure 5. From Table 4 it is observed that the first resonance frequency changes with respect to the inner ring width, keeping the second resonance frequency unaltered.

Table 4: Resonant frequency deviation due to inner ring (outer ring width $=0.5 \mathrm{~mm}$ constant)

\begin{tabular}{|l|c|c|c|c|c|c|}
\hline Inner ring(mm) & 2 & 2.2 & 2.4 & 2.6 & 2.8 & 3.0 \\
\hline $\begin{array}{l}\text { First resonant } \\
\text { frequency }\left(\boldsymbol{f}_{\mathbf{r 1}}\right) \\
(\mathbf{G H z})\end{array}$ & 4.42 & 4.38 & 4.3 & 4.28 & 4.24 & 4.20 \\
\hline $\begin{array}{l}\text { Second resonant } \\
\text { frequency }\left(\boldsymbol{f}_{\mathbf{r} 2}\right) \\
(\mathbf{G H z})\end{array}$ & 6.92 & 6.92 & 6.92 & 6.92 & 6.92 & 6.92 \\
\hline
\end{tabular}

Optimized parameters of the proposed geometry are listed in Table 5.

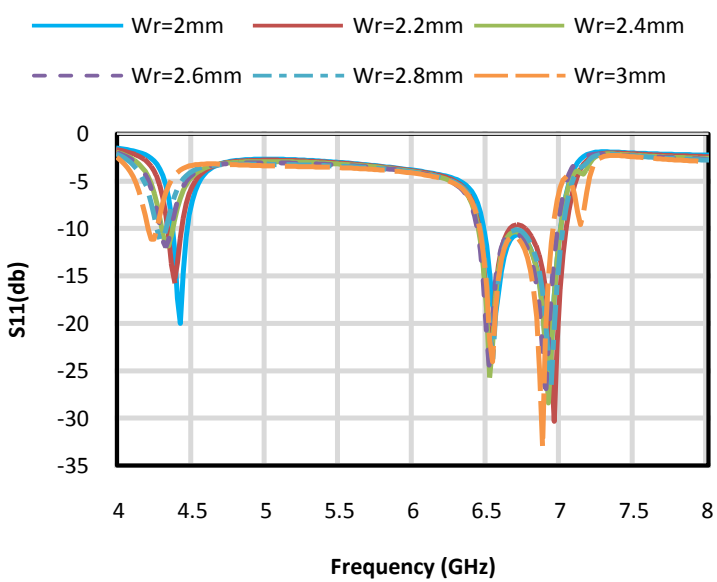

Figure 5: Return loss vs. frequency plot for variation in width of inner ring.

Table 5: Optimized parameters of geometry shown in Figure 1.

\begin{tabular}{|l|l|}
\hline Parameter & Value (mm) \\
\hline Width of antenna $(\mathrm{W})$ & 45 \\
\hline Length of antenna $(\mathrm{L})$ & 40 \\
\hline Width of mushroom $\left(\mathrm{W}_{\mathrm{m}}\right)$ & 6.4 \\
\hline Length of mushroom $\left(\mathrm{L}_{\mathrm{m}}\right)$ & 3.4 \\
\hline Width of inner ring $\left(\mathrm{W}_{\mathrm{r}}\right)$ & 2 \\
\hline Width of stub $\left(\mathrm{W}_{\mathrm{s}}\right)$ & 1.4 \\
\hline Length of stub $\left(\mathrm{L}_{\mathrm{s}}\right)$ & 11.6 \\
\hline Width of outer ring $\left(\mathrm{W}_{\mathrm{o}}\right)$ & 0.5 \\
\hline Gap between patch and outer ring $\left(\mathrm{g}_{\mathrm{po}}\right)$ & 0.3 \\
\hline Gap between stub and outer ring $\left(\mathrm{g}_{\mathrm{so}}\right)$ & 0.1 \\
\hline Dielectric constant $\left(\varepsilon_{\mathrm{r}}\right)$ & 4.4 \\
\hline Loss tangent (tan $\delta)$ & 0.01 \\
\hline Height of substrate $\left(\mathrm{h}_{\mathrm{s}}\right)$ & 3.175 \\
\hline
\end{tabular}

\section{EXPERIMENTAL VALIDATION OF THE GEOMETRY AND DISCUSSIONS}

The geometry shown in Figure 1 with its optimized Dimensions presented in Table 5 was fabricated and tested. The substrate used for the fabrication is the FR 4 glass epoxy with dielectric constant of 4.4, loss tangent $(\tan (\delta))=0.01$, and thickness of $3.175 \mathrm{~mm}$. A photograph of the fabricated prototype is shown in Figure 6(a) and its $S_{11}$ measurement setup is shown in Figure 6(b). Return loss characteristics of measured and simulated values are compared in Figure 7. The measured results fairly agree with the simulated values. 
From Figure 7 it may be noted that the proposed antenna is having the dual operating frequencies $4.42 \mathrm{GHz}$ and $6.92 \mathrm{GHz}$ and are similar to the simulated values. The simulated and measured $-10 \mathrm{~dB}$ bandwidths are $7.28 \%$ and $6.27 \%$ respectively for second resonance. However, it may be noted that at first resonance no bandwidth was observed. Radiation patterns of the antenna at various frequencies are given in Figure 8. From these patterns it is clear that a broad E-plane beamwidths can be obtained at the frequencies of interest.

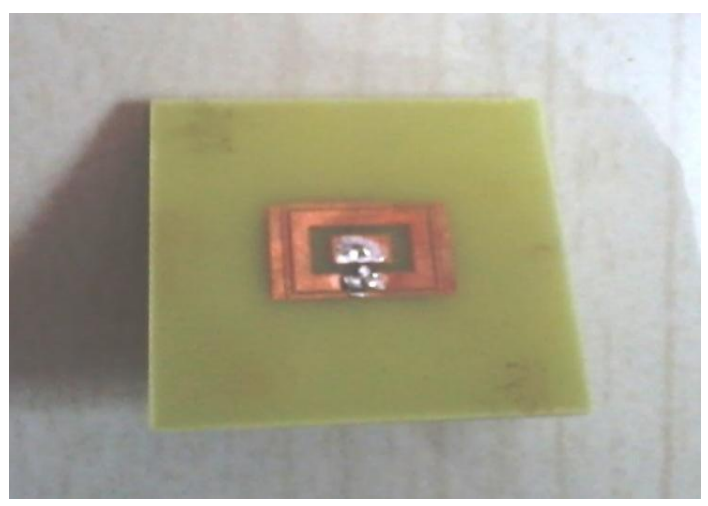

(a) Fabricated prototype

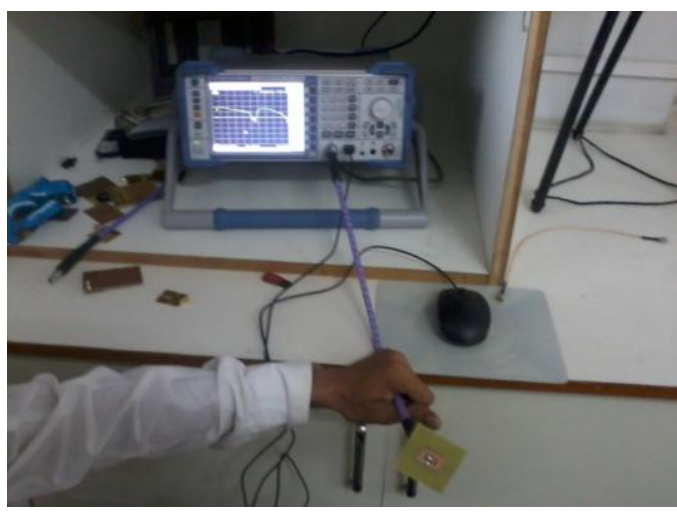

(b) $S_{11}$ measurement setup

Figure 6: Photographs of the fabricated antenna and its measurement Setup.

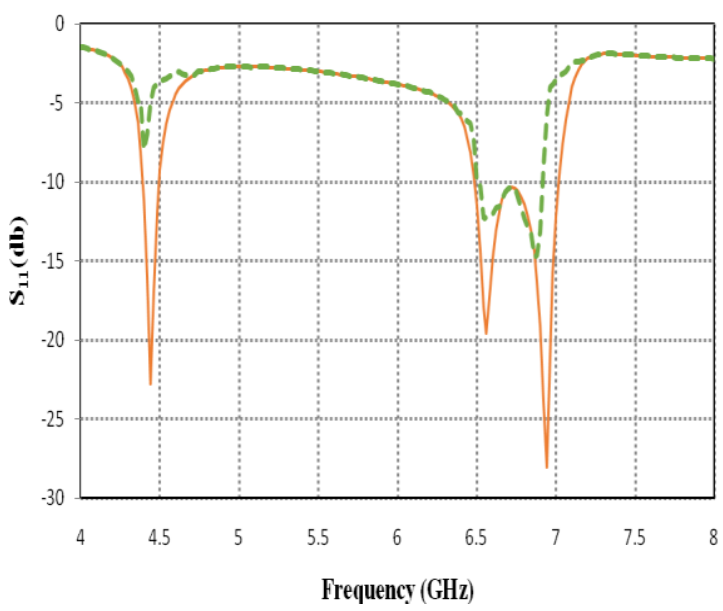

Figure 7: Return loss characteristic plot of the proposed antenna shown in Figure 1.
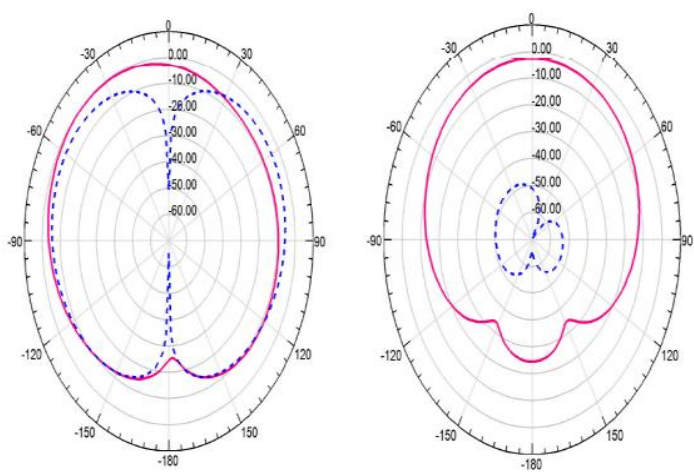

(a) E-plane and H-plane patterns at 4.42GHz
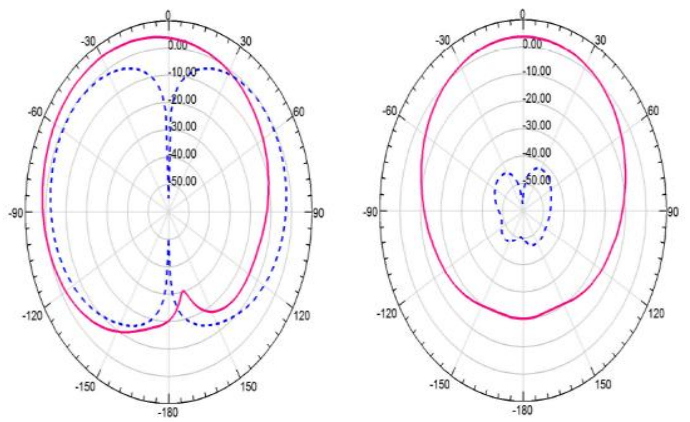

(b) E-plane and H-plane patterns at $6.56 \mathrm{GHz}$
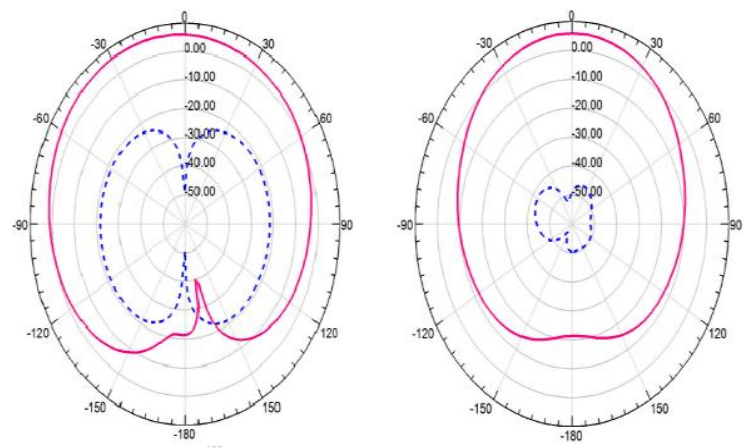

(c) E-plane and H-plane patterns at $6.92 \mathrm{GHz}$

Figure 8: $\mathrm{E}$ and $\mathrm{H}$ plane radiation pattern at different frequencies in operating band (Left side: E-plane patterns; Right side: H-plane patterns; Solid lines: copoln.; Dashed lines: cross poln.).

\section{CONCLUSIONS}

In this paper, a dual frequency ZOR patch antenna with two stubs has been presented. The added ZOR structure helps in achieving proper radiation characteristics despite of reduced antenna size. From this antenna we get the broader E- plane beamwidth at both first and second resonant frequencies with better bandwidth of about $7.8 \%$ at second resonant frequency as compared to the conventional patch antenna (2 3\%). The operating frequencies of the proposed antenna may be tuned by changing the stub length and the inner ring's dimensions. 
The overall ratio of resonant frequency $\left(f \mathrm{r}_{2} / f r_{1}\right)$ can be changed from 1.50 to 1.64 . Hence the proposed antenna is suitable for application where the broad E-plane beamwidths are required. The further work includes bandwidth enhancement of the proposed antenna keeping the beamwidth unaltered. Also, modeling of the antenna has to be carried out to better understand the working of proposed antenna.

\section{REFERENCES}

[1] R. Garg, P. Bhartia, I. Bahl, and A. Ittipiboon, Microstrip Antenna Design Handbook. Boston, MA: Artech House, 2000.

[2] C. A. Balanis, Antenna Theory: Analysis and Design, 3rd Edn. New York Wiley, 2005.

[3] T. P. Wong and K. M. Luk, "A wideband L-probe patch antenna array with wide beamwidth," IEEE Trans. Antennas Propag., vol. 51, no. 10, pp. 3012-3014, 2003.

[4] C. W. Su, S. K. Huang, and C. H. Lee, "CP microstrip antenna with wide beamwidth for GPS band application," Electron. Lett., vol. 43, no. 20, Sep. 2007.

[5] X. L. Bao and M. J. Ammann, "Dual-frequency dual circularly-polarized patch antenna with wide beamwidth," Electron. Lett., vol. 44, no. 21, pp. 1233$1234,2008$.

[6] Z.-S. Duan, S.-B. Qu, Y. Wu, and J.-Q. Zhang, "Wide bandwidth and broad beamwidth microstrip patch antenna," Electron. Lett., vol. 45, no. 5, pp. 249-250, Feb. 2009.

[7] S.-W.Qu, J.-L. Li, andQ.Xue, "Bowtie dipole antenna with wide beamwidth for base station application," IEEE Antennas Wireless Propag. Lett., vol. 6, pp. 293295, 2007.

[8] Z. N. Chen,W. K. Toh, and X. M. Qing, "A microstrip patch antenna with broadened beamwidth," Microw. Opt. Technol. Lett., vol. 50, no. 7, pp. 1885-1888, Jul. 2008.
[9] A. Sanada, C. Caloz, and T. Itoh, "Planar distributed structures with negative refractive properties," IEEE Trans. Microwave Theory Tech., vol. 52, no. 4, pp. 1252-1263, Apr. 2004.

[10] A. Lai, C. Caloz, and T. Itoh, "Composite right/lefthanded transmission line metamaterials," IEEE Microwave Mag., vol. 5, no. 3, pp. 34-50, Sep. 2004.

[11] A. Sanada, C. Caloz, and T. Itoh, "Zeroth order resonance in composite right/left-handed transmission line resonators," in Proc. Asia-Pacific Microwave Conf., Seoul, Korea, vol. 3, pp. 1588-1592 2003.

[12] Seung-Tae Ko and Jeong-Hae Lee, "Hybrid ZerothOrder Resonance Patch Antenna With Broad E-Plane Beamwidth," IEEE Transactions on Antennas and Propagation, Vol. 61, No. 1, January 2013

[13] C. Caloz and T. Itoh, Electromagnatic Metamaterials (Transmission Line theory and microwave application), Wiley IEEE Press 1st edition, 2005.

[14] J. G. Lee and J. H. Lee, "Zeroth order resonance loop antenna," IEEE Trans. Antennas Propag., vol. 55, no. 3 , pp. 994-997, Mar. 2007.

[15] R.W. Ziolkowski and A. Kipple, "Application of double negative metamaterials to increase the power radiated by electrically small antennas," IEEE Trans. Antennas Propag., vol.51, pp. 2626-2640, Oct. 2003.

[16] R. Das Saswato, "Metamaterials Arrive in Cell phones" (Online magazine article). Metamterial antennas. IEEE Spectrum. 2011-03-09.

[17] G. K. Singh, R. K. Chaudhary*, and K. V. Srivastava, "A compact zeroth order resonating antenna using complementary split ring resonator with mushroom type of structure," Progress In Electromagnetics Research Letters, Vol. 28, 139-148, 2012.

[18] HFSS13.0 User's Manual, Ansoft Corporation, Pittsburgh. 